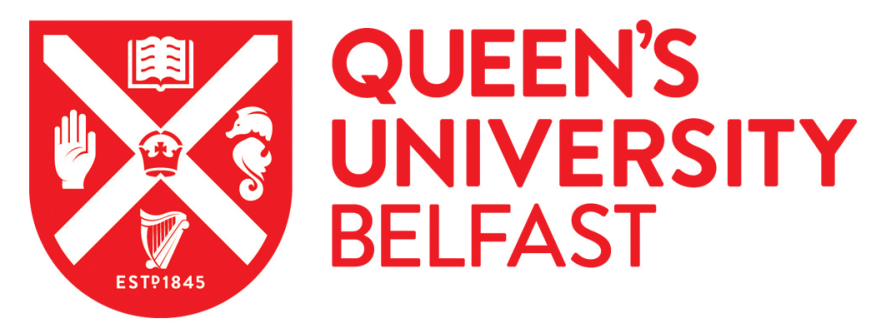

\title{
Controlled periodic illumination in semiconductor photocatalysis
}

Tokode, O., Prabhu, R., Lawton, L. A., \& Robertson, P. K. J. (2016). Controlled periodic illumination in semiconductor photocatalysis. Journal of Photochemistry and Photobiology A: Chemistry, 319-320, 96-106. https://doi.org/10.1016/j.jphotochem.2015.12.002

\section{Published in:}

Journal of Photochemistry and Photobiology A: Chemistry

\section{Document Version:}

Peer reviewed version

Queen's University Belfast - Research Portal:

Link to publication record in Queen's University Belfast Research Portal

\section{Publisher rights}

(C) 2016 Elsevier Ltd. This manuscript version is made available under the CC-BY-NC-ND 4.0 license http://creativecommons.org/licenses/bync-nd/4.0/ which permits distribution and reproduction for non-commercial purposes, provided the author and source are cited.

\section{General rights}

Copyright for the publications made accessible via the Queen's University Belfast Research Portal is retained by the author(s) and / or other copyright owners and it is a condition of accessing these publications that users recognise and abide by the legal requirements associated with these rights.

Take down policy

The Research Portal is Queen's institutional repository that provides access to Queen's research output. Every effort has been made to ensure that content in the Research Portal does not infringe any person's rights, or applicable UK laws. If you discover content in the Research Portal that you believe breaches copyright or violates any law, please contact openaccess@qub.ac.uk. 


\section{Controlled periodic illumination in semiconductor photocatalysis}

Oluwatosin Tokode ${ }^{1^{*}}$, Radhakrishna Prabhu², Linda Lawton ${ }^{3}$, Peter K. J. Robertson ${ }^{4}$. ${ }^{1}$ Department of Engineering, Coventry University College, Priory Street, Coventry CV1 $5 F B$, UK.

${ }^{2}$ School of Engineering, Robert Gordon University, Garthdee Road, Aberdeen, AB10 7GJ, UK.

${ }^{3}$ School of Pharmacy and Life Sciences, Robert Gordon University, Garthdee Road, Aberdeen, AB10 7GJ, UK.

${ }^{4}$ Centre for the Theory and Application of Catalysis (CenTACat), School of Chemistry and Chemical Engineering, Queen's University Belfast, Stranmillis Road, Belfast, BT9 $5 A G, U K$.

\section{Abstract}

Controlled periodic illumination is a hypothesis postulated in the early 1990s for enhancing the efficiency of semiconductor photocatalytic reactions. This technique has been proposed to improve photocatalytic efficiency by the nature of photon introduction alone. Before its application in semiconductor photocatalysis, controlled periodic illumination had been investigated in other fields including photosynthesis. This paper presents a detailed review of the state of the art research undertaken on the application of controlled periodic illumination in semiconductor photocatalysis. The review briefly introduces semiconductor photocatalysis, and then presents a detailed explanation of this technique, its importance to photocatalytic efficiency, an overview of previous results of its application in significant studies and present knowledge. Results from previous as well as some of the most recent studies indicate potential applications of controlled periodic illumination in areas other than just the improvement of the efficiency of the photocatalytic process.

\section{Keywords}

Controlled periodic illumination, Semiconductor photocatalysis, UV LEDs, LangmuirHinshelwood, Photonic efficiency

${ }^{1,4}$ Corresponding authors

Email: ${ }^{1}$ Oluwatosin.Tokode@cuc.coventry.ac.uk; ${ }^{4}$-p.robertson@qub.ac.uk 


\section{Introduction}

Over the years, it has been observed that certain pollutants cannot be treated by biological and conventional treatment methods because of their high chemical stability or strong resistance to mineralization. In such cases, it has been necessary to adopt a more reactive and efficient chemical treatment processes. A group of oxidation processes defined as advanced oxidation processes which operate at ambient temperature and pressure have gained prominence as alternative treatment methods. Advanced oxidation processes (AOPs) [1,2] are characterized by a unique chemical feature common to them: the in-situ generation of highly reactive hydroxyl radicals $\left(\mathrm{OH}^{\circ}\right)$ which drive the oxidation process by reacting with target molecules leading to the degradation and complete mineralisation of organic (and inorganic) pollutants in the environment [3]. They are also characterized by the selectivity of attack and versatility in the variety of ways $\mathrm{OH}^{\circ}$ are produced. The advanced oxidation processes for generation of $\mathrm{OH}$ radicals include; $\mathrm{H}_{2} \mathrm{O}_{2} / \mathrm{Fe}^{2+}$, $\mathrm{TiO}_{2} / \mathrm{UV}, \mathrm{O}_{3} / \mathrm{UV} / \mathrm{H}_{2} \mathrm{O}_{2}$ and $\mathrm{H}_{2} \mathrm{O}_{2} / \mathrm{UV}$ processes.

$\mathrm{TiO}_{2} / \mathrm{UV}$ is a heterogeneous photocatalytic process, which is an AOP employing $\mathrm{TiO}_{2}$ catalysts however, several other semiconductors such as $\mathrm{ZnO}$ [4], $\mathrm{SnO}_{2}$ and $\mathrm{CdS}$ have demonstrated capability as potential alternative materials to $\mathrm{TiO}_{2}$ [5]. Research on semiconductor photocatalysis has received significant attention after the electrochemical photolysis of water at $\mathrm{a} \mathrm{TiO}_{2}$ electrode was reported in 1972 by Fujishima and Honda [6]. Water molecules were decomposed by visible light into oxygen and hydrogen using $\mathrm{TiO}_{2}$ and platinum electrodes without any externally applied voltage. The water splitting was sustained by keeping the $\mathrm{TiO}_{2}$ and platinum electrodes apart according to the following schemes:

$$
\begin{aligned}
& \mathrm{TiO}_{2}+2 h v \rightarrow 2 \mathrm{e}^{-}+2 \mathrm{~h}^{+} \\
& \mathrm{H}_{2} \mathrm{O}+2 \mathrm{~h}^{+} \rightarrow 1 / 2 \mathrm{O}_{2}+2 \mathrm{H}^{+} \text {(at } \mathrm{TiO}_{2} \text { electrode) } \\
& 2 \mathrm{H}^{+}+2 \mathrm{e}^{-} \rightarrow \mathrm{H}_{2} \text { (at Pt electrode) } \\
& \text { The overall reaction was } \\
& \mathrm{H}_{2} \mathrm{O}+2 h v \rightarrow 1 / 2 \mathrm{O}_{2}+\mathrm{H}_{2}
\end{aligned}
$$

The fundamental principles, mechanisms and applications of semiconductor photocatalysis have now been widely studied and reported in the scientific literature 
[7-10]. Furthermore, this field continues to receive a significant amount of interest and research including industrial applications following the demonstration of the HondaFujishima effect.

\section{Semiconductor photocatalysis}

The band structure of a semiconductor exists as a series of energetic, tightly packed energy levels associated with atoms exhibiting covalent bonding which make up the valence band. Another series of similar energetic levels which are spatially diffuse and at a higher energy, associated with conduction make up the conduction band. The size of the energy gap ( $E_{\mathrm{bg}}$ ) (fig. 1) between the valence and the conduction band is responsible for the electrical conductivity of the semiconductor and its wavelength sensitivity to irradiance while in its undoped state [11].

\section{Figure 1.}

\subsection{Mechanism of semiconductor photocatalysis}

When photons having energy greater than or equal to the band gap are incident on the semiconductor, the photons may be absorbed by the material. This leads to photoexcitation resulting in promotion of an electron from the valence to the conduction band leaving behind a hole $\left(\mathrm{hvB}^{+}\right)$i.e. an electron vacancy. If the initial photo-excitation takes place in the semiconductor catalyst which then transfers energy or an electron to the adsorbed ground state molecule (substrate), a sensitized photo-reaction is said to have taken place. When the reverse takes place, the process is referred to as a catalyzed photo-reaction [12]. Upon band gap excitation, charge separation due to the promotion of an electron $\left(\mathrm{e}_{\mathrm{cb}}{ }^{-}\right)$from the valence to the conduction band takes place, generating a hole $\left(\mathrm{hvb}_{\mathrm{v}}{ }^{+}\right)$at the valence band in the process. The photogenerated charge carriers $\left(\mathrm{e}_{\mathrm{cb}}{ }^{-}\right.$and $\left.\mathrm{hvB}^{+}\right)$can follow several pathways which include recombination hence dissipating energy as heat, become trapped in a metastable state or take part in reduction and oxidation reactions on the catalyst surface. For productive photocatalysis to occur, trapping of the $e_{c b}{ }^{-} / h_{v b}{ }^{+}$or both is necessary. The trapping dynamics of photogenerated holes and electrons has been studied extensively by various authors and reviewed by Schneider et al. [13]. The primary steps after photon absorption by $\mathrm{TiO}_{2}$; a widely used photocatalyst in semiconductor photocatalysis are shown in reactions (5-11) [14]. 


$$
\begin{aligned}
& \mathrm{TiO}_{2}+h v \rightarrow \mathrm{e}_{\mathrm{cb}}{ }^{-}+\mathrm{hub}^{+} \\
& \mathrm{e}_{\mathrm{cb}}{ }^{-} \rightarrow \mathrm{e}_{\mathrm{tr}}{ }^{-} \\
& \mathrm{h}_{\mathrm{vb}^{+}} \rightarrow \mathrm{h}_{\mathrm{tr}^{+}} \\
& \mathrm{hvb}^{+}+\mathrm{H}_{2} \mathrm{O} \rightarrow \mathrm{OH}^{\cdot} \\
& \mathrm{e}_{\mathrm{cb}}{ }^{-}+\mathrm{O}_{2} \rightarrow \mathrm{O}_{2}{ }^{-} \\
& \mathrm{e}_{\mathrm{cb}}{ }^{-}+\mathrm{h}_{\mathrm{vb}}{ }^{+} \rightarrow \mathrm{TiO}_{2} \\
& \mathrm{etr}^{-}+\mathrm{htr}^{+} \rightarrow \mathrm{TiO}_{2}
\end{aligned}
$$

These reactions take place on the surface of the photocatalyst in traps located below the edge of the conduction band $[15,16]$. The highly reactive photogenerated $\mathrm{hvb}^{+}$and $\mathrm{e}_{\mathrm{cb}}{ }^{-}$are directly involved in the oxidation and reduction reactions respectively or indirectly through intermediate such as $\mathrm{OH}^{*}$ and $\mathrm{O}_{2}{ }^{-}$which are equally highly oxidizing and reducing species with high standard redox potentials $[17,18]$. Characteristic times for the primary processes based on measurements of laser flash photolysis have been investigated [7]. Schneider et al. have also recently compiled a similar table and separated the primary process into processes on the catalyst surface and inside the catalyst particle [13]. The characteristic times for the primary processes are shown in Table 1.

\section{Table 1.}

In Table 1, $\mathrm{Ti}^{\mathrm{IV}} \mathrm{OH}$ is the hydrated surface $\mathrm{TiO}_{2}, \mathrm{e}_{\mathrm{cb}}{ }^{-}$is the conduction-band electron, $e_{t r}{ }^{-}$is the trapped conduction-band electron, $\mathrm{h}_{\mathrm{vb}}{ }^{+}$is the valence-band hole, Red is the reductant (electron donor), $\mathrm{Ox}$ is the oxidant (electron acceptor), $\left\{>\mathrm{Ti} \mathrm{i}^{\prime \prime \prime} \mathrm{OH}\right\}$ is a surface-trapped conduction-band electron and $\left\{>\mathrm{Ti}^{1 \mathrm{~V}} \mathrm{OH}\right\}^{+}$is the valence-band hole trapped at the surface or surface-bound hydroxyl radical. The photogenerated hvB ${ }^{+}$ have a high quantum yield of $5.7 \times 10^{-2}$ for ordinary photocatalytic reactions [19]. They are readily trapped at the hydrated $\mathrm{TiO}_{2}$ surface during the oxidation of surface-bound $\mathrm{OH}^{-}$ion groups to $\mathrm{OH}^{*}$ because of their small effective mass [20]. The yield of $\mathrm{OH}^{*}$ is dependent on competition between oxidation of surface water by the $\mathrm{hvb}^{+}$and the rate of charge carrier recombination [21]. Furthermore, $\mathrm{OH}^{*}$ adsorbed on the surface of the hydroxylated $\mathrm{TiO}_{2}$ particle are easily assimilated and are indistinguishable from surface-trapped holes [10]. The resulting $\left\{\mathrm{Ti}^{i \vee} \mathrm{OH}\right\}^{+}{ }^{+}$ads is readily available for oxidative reactions with substrates adsorbed on the surface. 


\subsection{Efficiency of semiconductor photocatalysis}

In semiconductor photocatalysis, the efficiency of the photocatalytic process is referred to as the quantum yield, which can be defined as the number of molecules changed divided by the number of absorbed photons, assuming all photons are absorbed by the catalyst and losses due to light scattering are negligible [7]. For a species $i$, the quantum yield $\Phi$ is given by equation 12 .

$$
\Phi_{X}=\frac{ \pm(d[X] / d t)}{d[h v]_{a b s} / d t}
$$

$\Phi_{X}$ is the quantum yield for $X, d[X] / d t$ is the initial rate of formation or degradation of $X$ and $d[\mathrm{hv}] / d t$ is the rate of photon absorption by the catalyst.

Generally, photo-driven processes such as photography, photosynthesis and photocatalysis are preceded by photo-induced charge separation (5). The incident photons that initiate this process in photocatalysis are however, not efficiently used since charge carrier recombination (10 and 11) is a faster primary process than interfacial charge transfer ( 8 and 9 ). Hence, most electron-hole pairs recombine therefore limiting charge transfer which is necessary for initiating the desired redox reactions, ultimately this leads to low efficiencies [22]. When determining the quantum yield or efficiency, a combination of the total pathway probabilities for the hole and electron must be considered. This quantum yield is directly proportional to the electron transfer rate constant $\left(k_{\mathrm{t}}\right)$ and inversely proportional to the charge carrier recombination rate constant $\left(k_{r}\right)(13)$.

$$
\Phi \propto \frac{k_{t}}{k_{r}}
$$

For an ideal system, the quantum yield is directly proportional to the rate of charge transfer processes $\left(k_{C T}\right)$ and inversely proportional to the sum of both bulk and surface electron-hole recombination rate $\left(\mathrm{k}_{R}\right)$ and the charge transfer rate $\left(\mathrm{k}_{C T}\right)(14)$ :

$$
\Phi \propto \frac{k_{C T}}{k_{C T}+k_{R}}
$$

Diffusion of the products into the solution is assumed to be rapid without the reverse reaction of reduction by electrons and oxidation by holes. In the absence of 
recombination, quantum yield will have an ideal value of 1 [12] for photocatalytic processes. In real systems, however, recombination occurs and the concentration of holes and electrons at the surface is not equal [23].

\subsubsection{Measures of photocatalytic efficiency}

A variety of measures of efficiency are used in the literature on semiconductor photocatalysis. The quantum yield, $\Phi$ which takes into account the actual number of photons absorbed by the semiconductor catalyst has been sometimes referred to as the quantum efficiency, $\eta$ or photonic efficiency, $\zeta$ and determined using the number of photons incident on the catalyst. This latter definition is an accurate approximation of the efficiency and is a lower limit of the actual quantum yield. While determining quantum yields in semiconductor photocatalysis is feasible and has been demonstrated in several studies [22,24-27], it is experimentally difficult due to the significant amount of scattering, reflection, absorption and transmission of photons. As a result, most studies on semiconductor photocatalysis determine the rate of incident photons hence, employing photonic efficiency as a measure of efficiency. Differences in reactor geometry, light sources, reaction conditions and difficulties inherent in the determination of photon absorption by the catalyst have led to a proposed standardization of efficiencies. Relative photonic efficiency, $\zeta_{\mathrm{r}}[16]$ has been suggested as a protocol which affords comparisons of efficiencies from different studies and eliminates the confusion associated with quantum yield determination in the literature. Other suggested measures of efficiency include Electric energy per order/mass ( $\mathrm{E}_{\mathrm{EO}} / \mathrm{E}_{\mathrm{EM}}$ ) [28] which are based on electric energy consumption and mostly useful in economic analysis.

\subsubsection{Enhancement of photocatalytic efficiency}

A lot of effort has been directed at understanding the fundamental and engineering aspects of semiconductor photocatalysis with the primary aim of improving its efficiency [23]. Previous studies have shown that quantum yields in dilute aqueous suspensions are usually below $\sim 10 \%$ while quantum yields of oxidation of organic species in the gas phase exceed $50 \%$ under weak UV illumination $[7,12,29]$. Various methods of improving efficiency have been studied, for example doping of catalysts to enhance efficiency by inhibiting charge carrier recombination or improving light 
absorption is well reported in the literature [30-34]. The introduction of an extra electric field across the semiconductor photocatalyst to enhance the photocatalytic efficiency has been demonstrated [35]. The electric field promoted the separation of $e_{c b}-h_{v b}{ }^{+}$ pairs and prevented their recombination. These two examples employ the principles of band offsetting, defect introduction and electric force field that overcome the binding Coulombic forces and cause the dissociation of the electron-hole pair initially. In 1993 Sczechowski et al. [36] reported an impressive 500\% increase in the photonic efficiency of formate decomposition in $\mathrm{TiO}_{2}$ suspension through the technique of controlled periodic illumination (CPI).

\section{Controlled periodic illumination}

Controlled periodic illumination ( $\mathrm{CPI}$ ) in semiconductor photocatalysis is a hypothesis which was first investigated in 1993 by Sczechowski and co-workers. Prior to this report, it was known that information on the lifetimes of reactive intermediates in photochemical reactions could be obtained through periodic illumination [37-39]. The hypothesis suggests that upon illumination of a catalyst, there is a critical illumination time during which absorbed photons generate oxidizing species $\left(\mathrm{h}_{\mathrm{vb}}{ }^{+}\right)$on the surface of the catalyst. The generated species or their intermediates $\left(\mathrm{OH}^{\circ}\right)$ go on to react with substrates on the surface or in the bulk. Photons are not required for this latter step which also includes adsorption, desorption and diffusion hence, it can take place in the dark. After a critical recovery period in the dark, the photocatalyst can efficiently use photons again thus photons are reintroduced. CPI is therefore based on a series of alternate light and dark (TON/TOFF) periods (fig.2) which prevent the continuous introduction of photons that will result in the build-up of charges $\left(\mathrm{e}_{\mathrm{cb}}{ }^{-} / \mathrm{h}_{\mathrm{vb}}{ }^{+}\right)$and photogenerated intermediates $\left(\mathrm{OH}^{*} / \mathrm{O}_{2}{ }^{*-}\right)$. These charges and intermediate species are required for the desired photocatalytic reactions but their build-up can favour undesirable reactions resulting in a low efficiency of the photocatalytic process.

\section{Figure 2.}

The application of CPI will allow for the variation of TON/TOFF and calculation of the optimal amount of photons a photocatalyst can utilize in a given Ton period or under continuous illumination before saturation. It also makes determination of the specific light intensity required for photonic efficiency improvement possible. It was also 
suggested that CPI may influence selectivity of photocatalysis through changes in initial oxidation or relative rates of the remaining steps in the proposed pathways during reaction. Ultimately, an understanding of the mechanism of CPI will lead to design and synthesis of photocatalysts that can accommodate longer Ton and minimal Toff. An optimal photocatalyst in this hypothesis will require no Toff but will be highly efficient under continuous illumination.

Generally for CPI studies, the period of illumination is the time taken for a complete light time and dark time cycle and is the sum Ton + Toff while the duty cycle, $\gamma$ is the percentage of the period equivalent to a light time (15).

$$
\gamma=\frac{\mathrm{T}_{\mathrm{on}}}{\mathrm{T}_{\mathrm{on}}+\mathrm{T}_{\mathrm{off}}} \times 100 \%(15)
$$

At light times, the intensity of illumination is maximum hence, for a given reaction time under $\mathrm{CPI}$, the average intensity of illumination, is calculated as:

$$
I_{\text {avg }}=\gamma+I_{\max }
$$

While the photonic efficiency, $\zeta$ is determined as:

$$
\zeta_{X}=\frac{ \pm(d[X] / d t)}{d[h v]_{i n c} / d t}
$$

Where $\zeta_{X}$ is the photonic efficiency for $\boldsymbol{X}, \boldsymbol{d}[\boldsymbol{X}] / \boldsymbol{d} \boldsymbol{t}$ is the initial rate of formation or disappearance of $\boldsymbol{X}$ and $d[h v] / \boldsymbol{d} \boldsymbol{t}$ is the incident photon rate on the catalyst.

\subsection{Controlled periodic illumination in other fields}

The concept of periodic illumination has been applied in other fields for various purposes. It has been demonstrated to be a powerful tool in photolysis for studying the individual steps and mechanisms of chain reactions [37]. It has also been applied in the control of the formation of concentration patterns formed from instability of chemical reaction-diffusion systems; these patterns are known as Turing structures [40]. Of particular interest here is the demonstration of the efficient suppression of Turing structures using periodic illumination and the removal of defects in pre-existing Turing structures. Its investigation in the field of photosynthesis research which is characterised by photon saturation during ToN precedes photocatalysis and is also 
concerned with enhancement of efficiency. Earlier results in this area of research indicate an improved quantum yield under CPI [41] however, there are reports of equivalent yields under continuous and periodic illumination from other studies [42,43]. It is now well established that under periodic illumination, the photosynthetic apparatus being a very complex system, elicits various acclimatisation responses in plants leading to conflicting results on the effects of $\mathrm{CPI}$ on photosynthesis $[44,45]$.

\subsection{Experimental CPI studies in semiconductor photocatalysis}

The experimental studies by Sczechowski et al. provided preliminary results on the CPI hypothesis and its effects on photonic efficiency of photocatalytic reactions. Their pioneering study [36] reported a 500\% increase in photonic efficiency during formate ion oxidation (18) in $\mathrm{TiO}_{2}$ slurries. The oxidation of formate to $\mathrm{CO}_{2}$ was an appropriate reaction for testing this hypothesis due to the lack of competing intermediates.

$$
2 \mathrm{COOH}^{-}+\mathrm{O}_{2} \stackrel{\mathrm{hv} / \mathrm{TiO}_{2}}{\longrightarrow} 2 \mathrm{CO}_{2}+2 \mathrm{OH}^{-}
$$

Periodic illumination of the $\mathrm{TiO}_{2}$ slurry was simulated by wrapping sections of the bulb in aluminium foil (TOFF) with some sections exposed (TON) while the $\mathrm{TiO}_{2}$ suspension flowed underneath the light bulb in the channel reactor. The 5-fold increase in photonic efficiency which was due to CPI and the inadequacies of the channel reactor prompted the need for photoreactors which as a singular unit can periodically illuminate the semiconductor photocatalyst. Due to the inability of turning fluorescent bulbs on and off on a millisecond timescale, subsequent studies employed a Taylor vortex reactor (TVR) to simulate CPI [46]. Vortices formed in the TVR, transport catalyst particles into and out of the illuminated portion of the reactor. Creating vortices fast enough for the frequencies optimal for the CPI effect was, however, a significant design challenge.

\section{Figure 3.}

The results of the CPI effects were also investigated by Stewart and Fox [47], who studied the effect of varying the dark recovery time on the photonic efficiency of the photocatalytic oxidation of 1-octanol and photocatalytic reduction of $p$ nitroacetophenone in a non-aqueous media, using Degussa P25 $\mathrm{TiO}_{2}$. They reported a 1.8 fold improvement in the net photonic efficiency of 1-octanol oxidation to octanal but no improvement in the reduction of $p$-nitroacetophenone to $p$-aminoacetophenone. 
They suggested that a dark recovery time between intermittent excitation lowered the steady state concentration of the adsorbed intermediates and helped prevent charge carrier recombination which decreased efficiency. Foster et al. [48] investigated the mechanism of $\mathrm{CPI}$ effects using rotating ring disk photoelectrochemistry (RRDE). Their results suggested ordinary photoreactors at low light intensities could exhibit high photonic efficiencies but high photonic efficiencies at high light intensities would require photoreactors capable of periodically illuminating the photocatalyst. Buechler et al. investigated the CPI effect in the aqueous [49] and gaseous [50] phases using novel photoreactors capable of CPI. A $15 \%$ increase in photonic efficiency due to CPI was reported at light intensities above $0.5 \mathrm{~mW} / \mathrm{cm}^{2}$ for formate oxidation in the aqueous phase while photonic efficiency of trichloroethylene (TCE) oxidation in the diffusion-limited regime approached $\sim 100 \%$. All studies on CPI after Sczechowski et al. first demonstrated photonic efficiency enhancement using this technique corroborate the original hypothesis. This hypothesis, however, was later challenged by Cornu et al. [51] who demonstrated with formate oxidation that quantum yields under CPI did not exceed those under continuous illumination at equivalent photon absorption rates. Their results gave the first indication $\Phi$ values under CPI were always less than $\Phi$ under continuous illumination but equivalent at high frequency $\mathrm{CPI}$. A subsequent study by Buechler et al. in formate photocatalytic oxidation reached a similar conclusion [52]; they attributed the previously reported CPI effect to be due to mass transport limitations and slow or weak adsorption/reaction steps.

In addition to their study on quantum yields under CPI, Cornu et al. [53] also studied $\mathrm{CPI}$ in the stochastic regime and reported two rate-determining intermediates whose lifetimes and oxidizing/reducing potentials are dependent on the $\mathrm{pH}$ of the media. Their results also showed two transitions between low-frequency and high-frequency $\Phi$ values, the two transitions had characteristic times which were shown to be exponential functions of the $\mathrm{pH}$ of the media. For chain reactions in the stochastic regime, $\Phi$ will depend on the average concentration of the rate-determining intermediates. Further research into the understanding of the CPI effect was carried out by Wang et al. [54], where periodic illumination was created using laser pulse illumination having light-to-dark time ratio of $20 \mathrm{~ns}$ to $2 \mathrm{~s}$. They studied quantum yield of formaldehyde formation in aqueous methanolic $\mathrm{TiO}_{2}$ suspensions without mass transport limitations. They explained the increase in quantum yield of formaldehyde 
formation to be due to laser pulse-induced deaggregation of agglomerated $\mathrm{TiO}_{2}$ particles. Their results suggested deaggregation results in the exposure of additional sites for reactant adsorption hence, optimising catalyst surface area leading to increased reaction rates and quantum yields. The deaggregation concept was further developed with a novel mechanism proposed by Wang et al. to explain the CPI effect. The antenna mechanism [55] suggests that a long chain of agglomerated $\mathrm{TiO}_{2}$ particles not only increase catalyst surface area upon deaggregation but also acts as an antenna for transferring photon energy from the site of absorption to the site of reaction. The claim that no advantage accrued from the use of $\mathrm{CPI}$ over continuous illumination was further investigated by Chen et al. [56] who first studied CPI using UV LED sources [57] which were more suitable for the series of light and dark times required by CPI (fig. 4).

\section{Figure 4.}

UV LEDs were also employed by Tokode et al. [58] who used a controlled experiment design to study the CPI effect (Table 2). Both studies reported no photonic efficiency enhancement due to CPI at lavg equivalent to I under continuous illumination. These studies provide overwhelming experimental data which show that $\mathrm{CPI}$ alone is not sufficient to enhance the photonic efficiency of semiconductor photocatalysis.

\section{Table 2.}

\subsection{Theoretical CPI studies in semiconductor photocatalysis}

The vast majority of studies investigating CPI have relied on the experimental approach; these studies provided initial data for the development of mathematical models to simulate the observable phenomena on the semiconductor catalyst during $\mathrm{CPI}$. Two CPI models have been formulated and reported in the literature for determining quantum yields and photocatalytic rates of reaction under $\mathrm{CPI}$.

\subsubsection{Quantum yield CPI model}

A transient kinetic model to simulate the initial experimental evidence of the $\mathrm{CPI}$ hypothesis tested by Sczechowski et al. in terms of the fundamental steps was proposed by Upadhya and Ollis [59]. They identified factors which affect quantum yield and arrived at a kinetic scheme of four reactions leading to the equation development. 
A model for the quantum yield $\Phi,(19,20)$ as opposed to photonic efficiency was developed due to availability of data on photon absorption by the $\mathrm{TiO}_{2}$ catalyst. This model calculated quantum yield of the organic substrate was as an integral of the instantaneous quantum yield over time;

$$
\begin{array}{r}
\Phi_{\text {periodic }}=\frac{\int^{\mathrm{T}_{\mathrm{ON}}+\mathrm{T}_{\mathrm{OFF}} \mathrm{k}_{1} \mathrm{n}_{\mathrm{A}}\left(\mathrm{h}^{+}(\mathrm{t})\right) \Omega_{\mathrm{A}}(\mathrm{t}) \mathrm{dt}}}{\int^{\mathrm{T} O \mathrm{ON}_{\mathrm{g}} \mathrm{ldt}}} \\
\Phi_{\text {continuous }}=\frac{\int^{\mathrm{T}}{ }^{\mathrm{ON}} \mathrm{k}_{1} \mathrm{n}_{\mathrm{A}}\left(\mathrm{h}^{+}\right)_{\mathrm{SS}} \Omega_{\mathrm{Ass}} \mathrm{dt}}{\int^{\mathrm{T} \mathrm{ON}} \mathrm{kg}_{\mathrm{g}} \mathrm{ld}}
\end{array}
$$

Where $k_{1}$ is the oxidation reaction rate constant, $h^{+}$is the hole concentration, $\Omega_{\mathrm{A}}$ is the surface fractional coverage of organic substrate, $k_{g}$ is the light absorption rate constant, $n_{\mathrm{A}}$ is the number of surface sites for organic substrate, TON is the light time, ToFF is the dark time and $/$ is the incident light intensity. Their results at the time, corroborated the quantum yield enhancement result of Sczechowski and co-workers but more importantly, it provided knowledge of dioxygen and net charge concentration dynamics as a function of ToN/Toff during CPI (fig. 5).

\section{Figure 5.}

\subsubsection{The Langmuir-Hinshelwood CPI rate model}

For reactions on surfaces such as occur in semiconductor photocatalysis, the Langmuir-Hinshelwood (L-H) rate equation (24) is the simplest model consistent with Langmuir's equilibrium isotherm. The L-H rate model has a dependence upon concentration and is widely applied in determining rates of photocatalytic reactions in the literature with a close agreement when compared with experimental rate data [6062]. The photocatalytic rate, $r$ is calculated by the $\mathrm{L}-\mathrm{H}$ model as the product of the reaction rate constant, $k_{r}$ of surface species (photogenerated and substrate) and the extent of substrate adsorption, $K_{\text {ads. }}$. Competition for adsorption by other species is represented by adding the terms $K_{\text {ads }} C$ to the denominator.

$$
-\frac{d C}{d t}=r=k_{r} \frac{K_{a d s} C}{\left(1+K_{a d s} C\right)}
$$


Previous studies have established the dependence of photocatalytic rates on light intensity [63] leading to studies incorporating intensity into the L-H model [64]. With the intensity incorporated into equation 24 , the $\mathrm{L}-\mathrm{H}$ model is unsuitable for modelling reaction rates when the photocatalyst is under $\mathrm{CPI}$. The illumination intensity, its order and periodicity have to be accounted for in any rate model under CPI. Chen et al. [56] modified the L-H model by incorporating these parameters which account for the $\mathrm{CPI}$ effect (25) with the reaction assumed to take place on the outer surface of the photocatalyst particle.

$$
-\frac{d C}{d t}=r=k_{r}\left(\gamma I_{\max }\right)^{m} \frac{K_{a d s} C}{\left(1+K_{a d s} C\right)}
$$

Where $\mathrm{y}$ is the duty cycle of UV illumination, $I_{\max }$ is the light intensity (lavg $=\mathrm{Y} I \max$ ) and $m$ is the order of light intensity. The L-H CPI model produced photocatalytic rate trends at varying concentration and constant $\mathrm{y}$ in close agreement with the experimental data (fig. 6).

\section{Figure 6.}

In a recent study [65], the quantum yield CPI model and the L-H CPI model were employed in the photocatalytic degradation of methyl orange under CPI. The calculated values of $\Phi$ and $\zeta$ from the quantum yield CPI model and photonic efficiency experimental data respectively had different magnitudes but followed a similar trend (fig. 7). The L-H CPI model however, failed to predict the experimental rates due to the varying $y$ at constant concentration. The accuracy of the L-H CPI model is sensitive to lavg while the quantum yield CPI model accurately simulates quantum yield enhancement due to the CPI effect.

\section{Figure 7.}

\subsection{Recent results from CPI studies}

The body of work on CPI in semiconductor photocatalysis has disproved the original hypothesis by Sczechowski et al. The photonic efficiency enhancement due to CPI can be attained under continuous illumination at very weak illumination intensity. This technique, however, still receives attention from studies involving and investigating its 
effect on semiconductor photocatalysis as detailed in Table 3, which summarises the work that has been reported on CPI to date.

\section{Table 3.}

The mechanism for the hypothesis of residual disinfection effect which describes a further decrease of bacterial concentration long after photocatalyst illumination and photo-excitation has ceased was studied by Xiong and $\mathrm{Hu}$ [66]. They reported higher log-removal and inactivation of bacteria at high frequency $\mathrm{CPI}$ compared to continuous illumination at equivalent UV dosage. This result in semiconductor photocatalysis mediated inactivation of bacteria is significant because it mirrors the initial results of increase in photonic efficiency by pioneering studies in CPI. Tokode et al. [67] recently described a triple effect of $\mathrm{pH}, \mathrm{Y}$ and oxidizing species on the photonic efficiency of semiconductor photocatalysis. They describe how to optimize CPI and increase photonic efficiency without making any comparisons with continuous illumination. Two efficiency regimes were proposed under the experimental conditions of the study (fig.8).

\section{Figure 8.}

A recent study by Korovin et al. [68] has shown that frequency of periodic illumination is equally important as $\mathrm{y}$ in CPI. They employed UV LEDs in the photocatalytic oxidation of acetone vapour at very high frequency CPI. The results of Korovin and co-workers shows photonic efficiency, $\zeta$ under high frequency $\mathrm{CPI}$ is always lower than that of the continuous regime at equivalent average UV light intensities (fig. 9) but equals it at the maximum photonic efficiency value reached when the reaction becomes photon-limited [29]. This result is at variance with previous studies $[51,58]$ which report comparable efficiencies at equivalent average UV light intensities and further illustrates the need for more investigations into CPI for more understanding of its effects in semiconductor photocatalysis.

\section{Figure 9.}

\section{Conclusion}

The initial hypothesis put forward by Sczechowski et al. for improving the photonic efficiency of semiconductor photocatalysis through controlled periodic illumination has 
been a controversial subject having been both proved by initial studies [36,47,59] and disproved by subsequent studies $[51,65,68]$. Research investigating the mechanism of CPI has spanned two decades and is still ongoing $[66,67]$ despite not achieving its original purpose. This technique appears to only restore catalyst activity which is lost due to limitations in diffusion in large catalyst aggregates and is therefore a kinetic disguise because of the omitted rate-influencing reaction step. The mechanistic concept of the antenna mechanism and deaggregation proposed by Wang et al. [55] is currently employed by researchers in interpreting CPI data. Furthermore, the gains in photonic efficiency achieved under CPI alone can be achieved under low intensity continuous illumination. Photocatalytic experiments under CPI can, however be applied in providing kinetic information on the lifetimes of reactive intermediates on the photocatalyst surface, which determine the efficiency of the photocatalytic reaction. Its proposed contribution in determining the specific light intensity required by a semiconductor catalyst for improving photonic efficiency as well as the design and synthesis of an optimal catalyst still remain an objective of semiconductor photocatalysis research activity. 


\section{References}

[1] K. Topudurtir, S. Tay, E. Monschein, Advanced Photochemical Oxidation Processes. Handbook, (1998).

[2] R. Andreozzi, V. Caprio, A. Insola, R. Marotta, Advanced oxidation processes (AOP) for water purification and recovery, Catalysis today. 53 (1999) 51-59.

[3] O. Tokode, Photocatalytic destruction of volatile organic compounds from the oil and gas industry. (2014).

[4] A. Mclaren, T. Valdes-Solis, G. Li, S.C. Tsang, Shape and size effects of ZnO nanocrystals on photocatalytic activity, J. Am. Chem. Soc. 131 (2009) 12540-12541.

[5] M. Miyauchi, A. Nakajima, T. Watanabe, K. Hashimoto, Photocatalysis and photoinduced hydrophilicity of various metal oxide thin films, Chemistry of Materials. 14 (2002) 2812-2816.

[6] A. Fujishima, K. Honda, Photolysis-decomposition of water at the surface of an irradiated semiconductor, Nature. 238 (1972) 37-38.

[7] M.R. Hoffmann, S.T. Martin, W. Choi, D.W. Bahnemann, Environmental applications of semiconductor photocatalysis, Chem. Rev. 95 (1995) 69-96.

[8] A. Mills, S. Le Hunte, An overview of semiconductor photocatalysis, J. Photochem. Photobiol. A. 108 (1997) 1-35.

[9] M.A. Fox, M.T. Dulay, Heterogeneous photocatalysis, Chem. Rev. 93 (1993) 341 357.

[10] D. Lawless, N. Serpone, D. Meisel, Role of hydroxyl radicals and trapped holes in photocatalysis. A pulse radiolysis study, J. Phys. Chem. 95 (1991) 5166-5170.

[11] A.J. Nozik, Photoelectrochemistry: Applications to solar energy conversion, Annu. Rev. Phys. Chem. 29 (1978) 189-222.

[12] A.L. Linsebigler, G. Lu, J.T. Yates Jr, Photocatalysis on $\mathrm{TiO}_{2}$ surfaces: principles, mechanisms, and selected results, Chem. Rev. 95 (1995) 735-758.

[13] J. Schneider, M. Matsuoka, M. Takeuchi, J. Zhang, Y. Horiuchi, M. Anpo, D.W. Bahnemann, Understanding $\mathrm{TiO}_{2}$ photocatalysis: mechanisms and materials, Chem. Rev. 114 (2014) 9919-9986.

[14] S. Goldstein, D. Behar, J. Rabani, Nature of the oxidizing species formed upon UV photolysis of $\mathrm{C}-\mathrm{TiO}_{2}$ aqueous suspensions, The Journal of Physical Chemistry C. 113 (2009) 12489-12494. 
[15] S.H. Szczepankiewicz, J.A. Moss, M.R. Hoffmann, Slow surface charge trapping kinetics on irradiated $\mathrm{TiO}_{2}$, The Journal of Physical Chemistry B. 106 (2002) 29222927.

[16] H. Wang, J. He, G. Boschloo, H. Lindström, A. Hagfeldt, S. Lindquist, Electrochemical investigation of traps in a nanostructured $\mathrm{TiO}_{2}$ film, The Journal of Physical Chemistry B. 105 (2001) 2529-2533.

[17] D.T. Sawyer, J.S. Valentine, How super is superoxide? Acc. Chem. Res. 14 (1981) 393-400.

[18] P.M. Wood, The potential diagram for oxygen at pH 7, Biochem. J. 253 (1988) 287-289.

[19] K. Ishibashi, A. Fujishima, T. Watanabe, K. Hashimoto, Quantum yields of active oxidative species formed on $\mathrm{TiO}_{2}$ photocatalyst, J. Photochem. Photobiol. A. 134 (2000) 139-142.

[20] S.H. Szczepankiewicz, J.A. Moss, M.R. Hoffmann, Electron traps and the stark effect on hydroxylated titania photocatalysts, The Journal of Physical Chemistry B. 106 (2002) 7654-7658.

[21] R. Gao, J. Stark, D.W. Bahnemann, J. Rabani, Quantum yields of hydroxyl radicals in illuminated $\mathrm{TiO}_{2}$ nanocrystallite layers, J. Photochem. Photobiol. A. 148 (2002) 387-391.

[22] M.A. Grela, A.J. Colussi, Kinetics of stochastic charge transfer and recombination events in semiconductor colloids. Relevance to photocatalysis efficiency, J. Phys. Chem. 100 (1996) 18214-18221.

[23] D.F. Ollis, H. Al-Ekabi, Photocatalytic Purification and Treatment of Water and Air: Proceedings of the 1st International Conference on $\mathrm{TiO}_{2}$ Photocatalytic Purification and Treatment of Water and Air, London, Ontario, Canada, 8-13 November, 1992, Elsevier Science Ltd, 1993.

[24] A. Salinaro, A.V. Emeline, J. Zhao, H. Hidaka, V.K. Ryabchuk, N. Serpone, Terminology, relative photonic efficiencies and quantum yields in heterogeneous 
photocatalysis. Part II: Experimental determination of quantum yields, Pure and applied chemistry. 71 (1999) 321-335.

[25] M.L. Satuf, R.J. Brandi, A.E. Cassano, O.M. Alfano, Experimental method to evaluate the optical properties of aqueous titanium dioxide suspensions, Ind Eng Chem Res. 44 (2005) 6643-6649.

[26] Y. Du, J. Rabani, Determination of quantum yields in two-dimensional scattering systems, J. Photochem. Photobiol. A. 162 (2004) 575-578.

[27] C. Wang, J. Rabani, D.W. Bahnemann, J.K. Dohrmann, Photonic efficiency and quantum yield of formaldehyde formation from methanol in the presence of various TiO 2 photocatalysts, J. Photochem. Photobiol. A. 148 (2002) 169-176.

[28] J.R. Bolton, K.G. Bircher, W. Tumas, C.A. Tolman, Figures-of-merit for the technical development and application of advanced oxidation technologies for both electric-and solar-driven systems (IUPAC Technical Report), Pure and Applied Chemistry. 73 (2001) 627-637.

[29] Y. Ohko, K. Hashimoto, A. Fujishima, Kinetics of photocatalytic reactions under extremely low-intensity UV illumination on titanium dioxide thin films, The Journal of Physical Chemistry A. 101 (1997) 8057-8062.

[30] J. Disidier, J. Herrmann, P. Pichat, A Photoconductivity study of electron transfer from the ultraviolet-illuminated support to the metal and of the influence of hydrogen, J.Chem.Soc.Faraday Trans.I. 79 (1983) 651-660.

[31] S. Sakthivel, M. Shankar, M. Palanichamy, B. Arabindoo, D. Bahnemann, V. Murugesan, Enhancement of photocatalytic activity by metal deposition: 
characterisation and photonic efficiency of $\mathrm{Pt}, \mathrm{Au}$ and $\mathrm{Pd}$ deposited on $\mathrm{TiO}_{2}$ catalyst, Water Res. 38 (2004) 3001-3008.

[32] M.K. Seery, R. George, P. Floris, S.C. Pillai, Silver doped titanium dioxide nanomaterials for enhanced visible light photocatalysis, J. Photochem. Photobiol. A. 189 (2007) 258-263.

[33] T. Xu, L. Zhang, H. Cheng, Y. Zhu, Significantly enhanced photocatalytic performance of $\mathrm{ZnO}$ via graphene hybridization and the mechanism study, Applied Catalysis B: Environmental. 101 (2011) 382-387.

[34] X. Zong, H. Yan, G. Wu, G. Ma, F. Wen, L. Wang, C. Li, Enhancement of photocatalytic $\mathrm{H}_{2}$ evolution on CdS by loading $\mathrm{MoS}_{2}$ as cocatalyst under visible light irradiation, J. Am. Chem. Soc. 130 (2008) 7176-7177.

[35] Z. Jiang, H. Wang, H. Huang, C. Cao, Photocatalysis enhancement by electric field: $\mathrm{TiO}_{2}$ thin film for degradation of dye X-3B, Chemosphere. 56 (2004) 503-508.

[36] J.G. Sczechowski, C.A. Koval, R.D. Noble, Evidence of critical illumination and dark recovery times for increasing the photoefficiency of aqueous heterogeneous photocatalysis, J. Photochem. Photobiol. A. 74 (1993) 273-278.

[37] W. Haden Jr, O. Rice, The Chain Photolysis of Acetaldehyde in Intermittent Light, J. Chem. Phys. 10 (1942) 445-460.

[38] W.A. Noyes, P.A. Leighton, Photochemistry of gases, (1966).

[39] G. Burnett, H. Melville, Propagation and Termination Coefficients for Vinyl Acetate Photopolymerization, Nature. 156 (1945) 661.

[40] A.K. Horváth, M. Dolnik, A.P. Munuzuri, A.M. Zhabotinsky, I.R. Epstein, Control of Turing structures by periodic illumination, Phys. Rev. Lett. 83 (1999) 2950.

[41] R. Emerson, W. Arnold, A Separation of the Reactions in Photosynthesis by Means of Intermittent Light, J. Gen. Physiol. 15 (1932) 391-420.

[42] J.P. Gaudillère, Effect of periodic oscillations of artificial light emission on photosynthetic activity, Physiol. Plantarum. 41 (1977) 95-98.

[43] J. Gaudillere, J. Drevon, J. Bernoud, F. Jardinet, M. Euvrard, Effects of periodic fluctuations of photon flux density on anatomical and photosynthetic characteristics of soybean leaves, Photosynthesis Res. 13 (1987) 81-89.

[44] M. Kono, I. Terashima, Long-term and short-term responses of the photosynthetic electron transport to fluctuating light, Journal of Photochemistry and Photobiology B: Biology. 137 (2014) 89-99. 
[45] J.U. Grobbelaar, L. Nedbal, V. Tichý, Influence of high frequency light/dark fluctuations on photosynthetic characteristics of microalgae photoacclimated to different light intensities and implications for mass algal cultivation, J. Appl. Phycol. 8 (1996) 335-343.

[46] J.G. Sczechowski, C.A. Koval, R.D. Noble, A Taylor vortex reactor for heterogeneous photocatalysis, Chemical Engineering Science. 50 (1995) 3163-3173.

[47] G. Stewart, M.A. Fox, The effect of dark recovery time on the photoefficiency of heterogeneous photocatalysis by $\mathrm{TiO}_{2}$ suspended in non-aqueous media, Research on chemical intermediates. 21 (1995) 933-938.

[48] N.S. Foster, C.A. Koval, J.G. Sczechowski, R.D. Noble, Investigation of controlled periodic illumination effects on photo-oxidation processes at titanium dioxide films using rotating ring disk photoelectrochemistry, J Electroanal Chem. 406 (1996) 213217.

[49] K.J. Buechler, C.H. Nam, T.M. Zawistowski, R.D. Noble, C.A. Koval, Design and evaluation of a novel-controlled periodic illumination reactor to study photocatalysis, Ind Eng Chem Res. 38 (1999) 1258-1263.

[50] K.J. Buechler, R.D. Noble, C.A. Koval, W.A. Jacoby, Investigation of the effects of controlled periodic illumination on the oxidation of gaseous trichloroethylene using a thin film of $\mathrm{TiO}_{2}$, Ind Eng Chem Res. 38 (1999) 892-896.

[51] C.J. Cornu, A. Colussi, M.R. Hoffmann, Quantum yields of the photocatalytic oxidation of formate in aqueous $\mathrm{TiO} 2$ suspensions under continuous and periodic illumination, The Journal of Physical Chemistry B. 105 (2001) 1351-1354.

[52] K.J. Buechler, T.M. Zawistowski, R.D. Noble, C.A. Koval, Investigation of the mechanism for the controlled periodic illumination effect in $\mathrm{TiO}_{2}$ photocatalysis, Ind Eng Chem Res. 40 (2001) 1097-1102.

[53] C. Cornu, A. Colussi, M. Hoffmann, Time scales and $\mathrm{pH}$ dependences of the redox processes determining the photocatalytic efficiency of $\mathrm{TiO} 2$ nanoparticles from periodic illumination experiments in the stochastic regime, The Journal of Physical Chemistry B. 107 (2003) 3156-3160.

[54] C. Wang, R. Pagel, D.W. Bahnemann, J.K. Dohrmann, Quantum yield of formaldehyde formation in the presence of colloidal $\mathrm{TiO}_{2}$-based photocatalysts: effect 
of intermittent illumination, platinization, and deoxygenation, The Journal of Physical Chemistry B. 108 (2004) 14082-14092.

[55] C. Wang, R. Pagel, J.K. Dohrmann, D.W. Bahnemann, Antenna mechanism and deaggregation concept: novel mechanistic principles for photocatalysis, Comptes Rendus Chimie. 9 (2006) 761-773.

[56] H. Chen, Y. Ku, A. Irawan, Photodecomposition of o-cresol by UV-LED/TiO 2 process with controlled periodic illumination, Chemosphere. 69 (2007) 184-190.

[57] O. Tokode, R. Prabhu, L.A. Lawton, P.K.J Robertson, UV LED Sources for Heterogeneous Photocatalysis, in "Environmental Photochemistry Part III" ,eds. D. W. Bahnemann and P.K.J Robertson, Springer-Verlag Berlin Heidelberg. 2015, 159-180

[58] O.I. Tokode, R. Prabhu, L.A. Lawton, P.K.J Robertson, Effect of controlled periodic-based illumination on the photonic efficiency of photocatalytic degradation of methyl orange, Journal of Catalysis. 290 (2012) 138-142.

[59] S. Upadhya, D.F. Ollis, Simple photocatalysis model for photoefficiency enhancement via controlled, periodic illumination, The Journal of Physical Chemistry B. 101 (1997) 2625-2631.

[60] K.V. Kumar, K. Porkodi, F. Rocha, Langmuir-Hinshelwood kinetics-a theoretical study, Catalysis Communications. 9 (2008) 82-84.

[61] A. Mills, J. Wang, D.F. Ollis, Dependence of the kinetics of liquid-phase photocatalyzed reactions on oxygen concentration and light intensity, Journal of Catalysis. 243 (2006) 1-6.

[62] D.F. Ollis, Kinetic disguises in heterogeneous photocatalysis, Topics in catalysis. 35 (2005) 217-223.

[63] D.F. Ollis, E. Pelizzetti, N. Serpone, Photocatalyzed destruction of water contaminants, Environ. Sci. Technol. 25 (1991) 1522-1529.

[64] M. Behnajady, N. Modirshahla, R. Hamzavi, Kinetic study on photocatalytic degradation of $\mathrm{Cl}$ Acid Yellow 23 by ZnO photocatalyst, J. Hazard. Mater. 133 (2006) 226-232.

[65] O. Tokode, R. Prabhu, L.A. Lawton, P.K.J. Robertson, Mathematical modelling of quantum yield enhancements of methyl orange photooxidation in aqueous $\mathrm{TiO}_{2}$ 
suspensions under controlled periodic UV LED illumination, Applied Catalysis B: Environmental. 156 (2014) 398-403.

[66] P. Xiong, J. Hu, Inactivation/reactivation of antibiotic-resistant bacteria by a novel UVA/LED/TiO 2 system, Water Res. 47 (2013) 4547-4555.

[67] O. Tokode, R. Prabhu, L.A. Lawton, P.K. Robertson, The effect of $\mathrm{pH}$ on the photonic efficiency of the destruction of methyl orange under controlled periodic illumination with UV-LED sources, Chem. Eng. J. 246 (2014) 337-342.

[68] E. Korovin, D. Selishchev, A. Besov, D. Kozlov, UV-LED $\mathrm{TiO}_{2}$ photocatalytic oxidation of acetone vapor: Effect of high frequency controlled periodic illumination, Applied Catalysis B: Environmental. 163 (2015) 143-149.

[69] X. Zhang, Y.L. Chen, R. Liu, D.P. Tsai, Plasmonic photocatalysis, Reports on Progress in Physics. 76 (2013) 046401. 


\section{Captions for Tables}

Table 1: Characteristic times of primary processes in semiconductor photocatalysis of $\mathrm{TiO}_{2}$.

Table 2: Controlled experiment design used by Tokode et al. for studying the CPI effect.

Table 3: Bibliography of work involving CPI in semiconductor photocatalysis in chronological order 


\begin{tabular}{|c|c|}
\hline PRIMARY PROCESS & CHARACTERISTIC TIMES \\
\hline \multicolumn{2}{|l|}{ Charge-carrier generation } \\
\hline $\mathrm{TiO}_{2}+h_{v} \rightarrow \mathbf{h}_{\mathrm{vb}}^{+}+\mathbf{e}_{\mathrm{cb}}^{-}$ & Very fast (fs) \\
\hline \multicolumn{2}{|l|}{ Charge-carrier trapping } \\
\hline $\mathbf{h}_{\mathrm{vb}}^{+}+>\mathrm{Ti}^{\mathrm{IV}} \mathbf{O H} \rightarrow\left\{\mathrm{Ti}^{\mathrm{IV}} \mathbf{O H}^{\bullet}\right\}^{+}$ & Fast (10 ns) \\
\hline $\mathbf{e}_{\mathbf{c b}}^{-}+\mathrm{Ti}^{\mathrm{IV}} \mathbf{O H} \leftrightarrow\left\{\mathrm{Ti}^{\mathrm{III}} \mathbf{O H}\right\}$ & Shallow trap (100 ps)(dynamic \\
\hline \multirow[t]{2}{*}{$\mathbf{e}_{\mathbf{c b}}^{-}+>\mathrm{Ti}^{\mathrm{IV}} \rightarrow \mathrm{Ti}^{\mathrm{III}}$} & equilibrium) \\
\hline & Deep trap (10 ns) (irreversible) \\
\hline \multicolumn{2}{|l|}{ Charge-carrier recombination } \\
\hline $\mathbf{e}_{\mathbf{c b}}^{-}+\left\{>\mathbf{T i}^{\mathrm{IV}} \mathbf{O H}^{\bullet}\right\}^{+} \rightarrow \mathbf{T i}^{\mathrm{IV}} \mathbf{O H}$ & Slow (100 ns) \\
\hline $\mathbf{h}_{\mathbf{v b}}^{+}+\left\{>\mathbf{T i}^{\mathrm{III}} \mathbf{O H}\right\} \rightarrow \mathbf{T i}^{\mathbf{I V}} \mathbf{O H}$ & Fast (10 ns) \\
\hline \multicolumn{2}{|l|}{ Interfacial charge transfer } \\
\hline$\left\{>\mathbf{T i}^{\mathrm{IV}} \mathbf{O H}^{\bullet}\right\}^{+}+\mathbf{R e d} \rightarrow$ & Slow (100 ns) \\
\hline$>\mathrm{Ti}^{\mathrm{IV}} \mathbf{O H}+\mathrm{Red}^{\bullet+}$ & Very slow (ms) \\
\hline $\mathbf{e}_{\mathrm{tr}}^{-}+\mathbf{O x} \rightarrow \mathrm{Ti}^{\mathrm{IV}} \mathbf{O H}+\mathbf{O x ^ { \bullet - }}$ & \\
\hline
\end{tabular}

Table 1.

\begin{tabular}{cccc}
\hline EXPERIMENT & $\begin{array}{c}\text { DEPENDENT } \\
\text { VARIABLE }\end{array}$ & $\begin{array}{c}\text { INDEPENDENT } \\
\text { VARIABLE }\end{array}$ & $\begin{array}{c}\text { CONTROLLED } \\
\text { VARIABLE }\end{array}$ \\
\hline 1 & $\zeta$ & ToN/TOFF & Period \\
2 & $\zeta$ & ToFF / Period & ToN \\
3 & $\zeta$ & Ton / Period & ToFF \\
\hline
\end{tabular}

Table 2. 


\begin{tabular}{|c|c|c|c|}
\hline Author & Type/Phase of study & Study & Year \\
\hline Sczechowski et al. & Experimental/Liquid & CPI hypothesis & 1993 \\
\hline Sczechowski et al. & Experimental/Liquid & Photonic efficiency & 1993 \\
\hline Sczechowski et al. & Experimental/Liquid & $\begin{array}{c}\text { Taylor vortex reactor } \\
\text { (TVR) }\end{array}$ & 1995 \\
\hline Stewart and Fox & Experimental/Liquid & Effect of $T_{\text {off }}$ & 1995 \\
\hline Foster et al. & Experimental/Liquid & $\begin{array}{c}\text { Rotating Ring Disk } \\
\text { Electrochemistry } \\
\text { (RRDE)/ Effect of CPI }\end{array}$ & 1996 \\
\hline Upadhya and Ollis & Theoretical & $\begin{array}{c}\text { Transient kinetic } \\
\text { model }\end{array}$ & 1997 \\
\hline Buechler et al. & Experimental/Gaseous & Effect of CPI & 1999 \\
\hline Buechler et al. & Experimental/Gaseous & $\begin{array}{l}\text { Rotating Disk Reactor } \\
\text { (RDR) }\end{array}$ & 1999 \\
\hline Cornu et al. & Experimental/Liquid & $\begin{array}{l}\text { Effect of CPI on } \\
\text { quantum yield }\end{array}$ & 2001 \\
\hline Buechler et al. & Experimental/Liquid & Mechanism of $\mathrm{CPI}$ & 2001 \\
\hline Cornu et al. & Experimental/Liquid & Effect of $\mathrm{pH}$ on $\mathrm{CPI}$ & 2003 \\
\hline Wang and $\mathrm{Ku}$ & Experimental/Liquid & Effect of CPI & 2006 \\
\hline Wang et al. & Experimental/Liquid & $\begin{array}{c}\text { Deaggregation } \\
\text { concept }\end{array}$ & 2004 \\
\hline Chen et al. & Experimental/Liquid & $\begin{array}{c}\text { Effect of CPI on } \\
\text { photonic efficiency }\end{array}$ & 2007 \\
\hline Chen et al. & Experimental/Liquid & Effect of CPI & 2007 \\
\hline Tokode et al. & Experimental/Liquid & $\begin{array}{l}\text { Effect of CPI on } \\
\text { photonic efficiency }\end{array}$ & 2012 \\
\hline Xiong and $\mathrm{Hu}$ & Experimental/Liquid & $\begin{array}{c}\text { Residual disinfection } \\
\text { effect }\end{array}$ & 2013 \\
\hline Tokode et al. & Experimental/Liquid & $\begin{array}{c}\text { Effect of pH on } \\
\text { photonic efficiency }\end{array}$ & 2014 \\
\hline Tokode et al. & Theoretical & CPI modelling & 2014 \\
\hline Rasoulifard et al. & Experimental/Liquid & Effect of CPI & 2014 \\
\hline Korovin et al. & Experimental/Gaseous & High frequency CPI & 2015 \\
\hline
\end{tabular}


Table 3. 


\section{Captions for Figures}

Figure 1: (a) Energy bands in solids: (a) insulator, (b) semiconductor, (c) conductor; (b) band gaps of common semiconductor photocatalysts [Reprinted with permission from [69]. Copyright 2013, IOP publishing].

Figure 2: Schematic of CPI according to the original hypothesis by Sczechowski and co-workers.

Figure 3: A section through a TVR during operation [Reprinted with permission from [46]. Copyright 1995, Elsevier].

Figure 4: UV LED illuminated photoreactor designed by Chen et al. [Reprinted with permission from [56]. Copyright 2007, Elsevier].

Figure 5: Calculation of dioxygen and net charge concentration as a function of time by Upadhya and Ollis. [Reprinted with permission from [59]. Copyright 1997, American Chemical Society].

Figure 6: Rate comparison between experimental data and L-H CPI model by Chen et al. [Reprinted with permission from [56]. Copyright 2007, Elsevier].

Figure 7: Comparison between experimental and model data for (a) L-H CPI rate model, (b) quantum yield CPI model. [Reprinted with permission from [65]. Copyright 2014, Elsevier].

Figure 8: Photonic efficiency regimes due to the triple effect of $\mathrm{pH}, \mathrm{\gamma}$ and oxidizing species.

Figure 9: Comparison between photonic efficiencies under CPI (box) and continuous illumination (triangle) at equivalent average light intensities by Korovin et al. [Reprinted with permission from [68]. Copyright 2015, Elsevier]. 
(a)

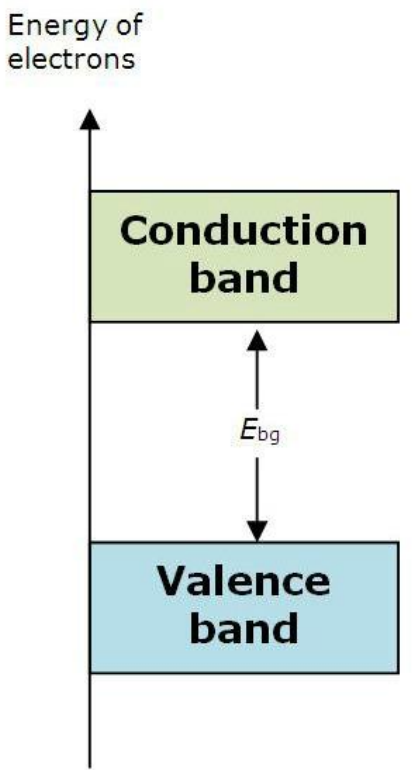

(a)

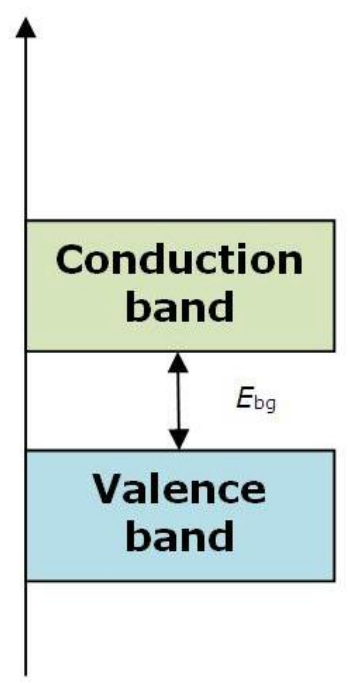

(b)

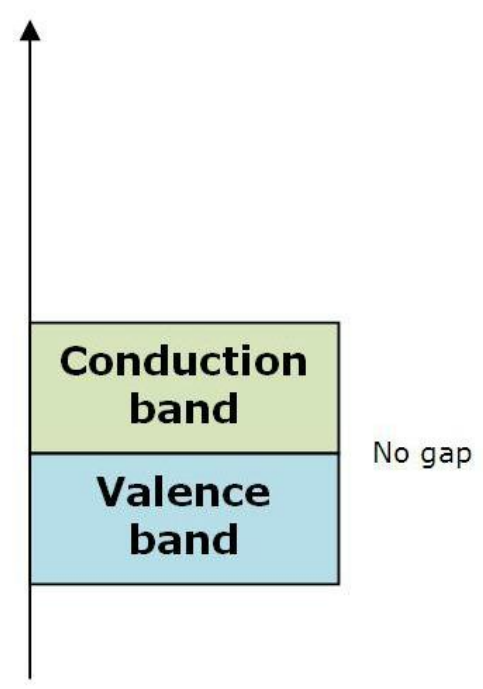

(c)

(b)

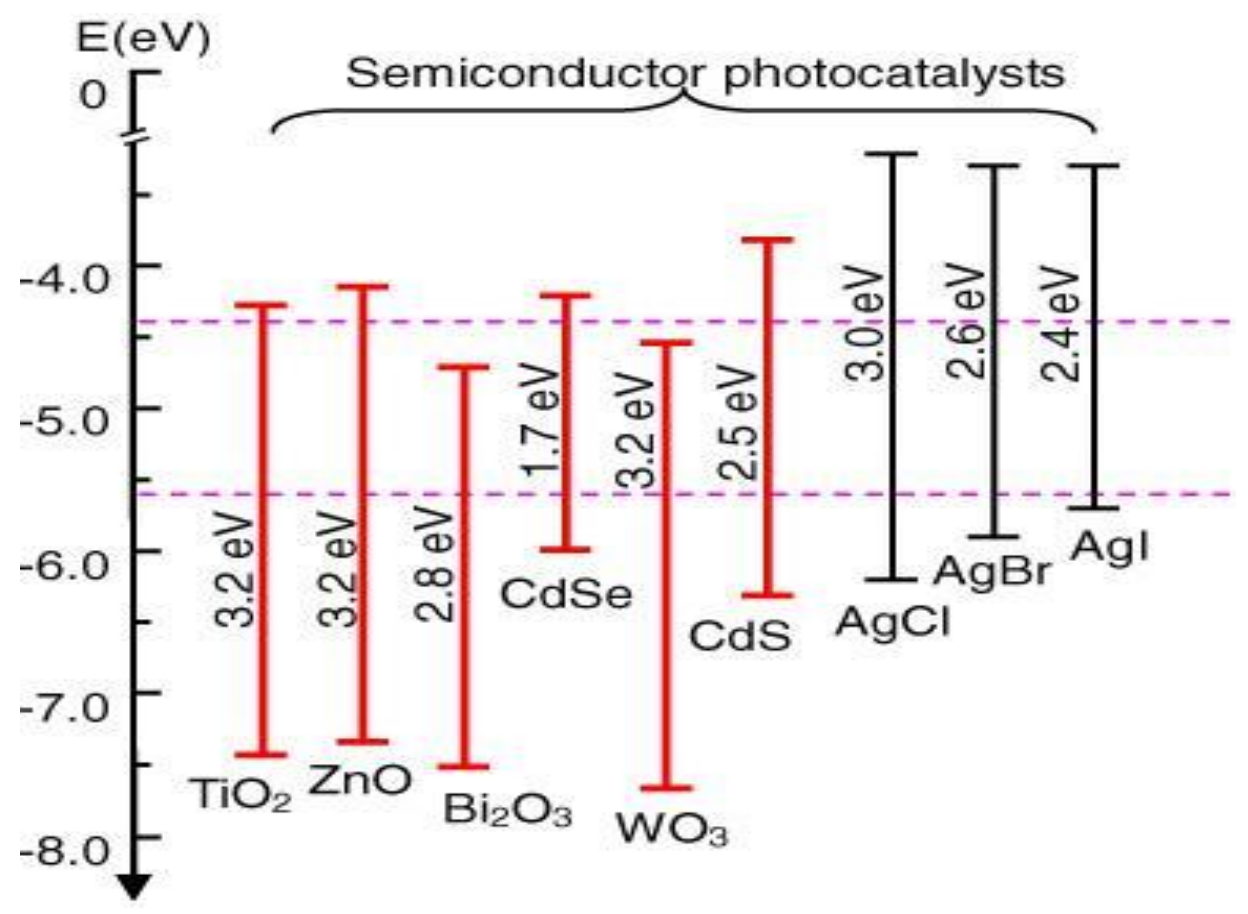

Figure 1. 


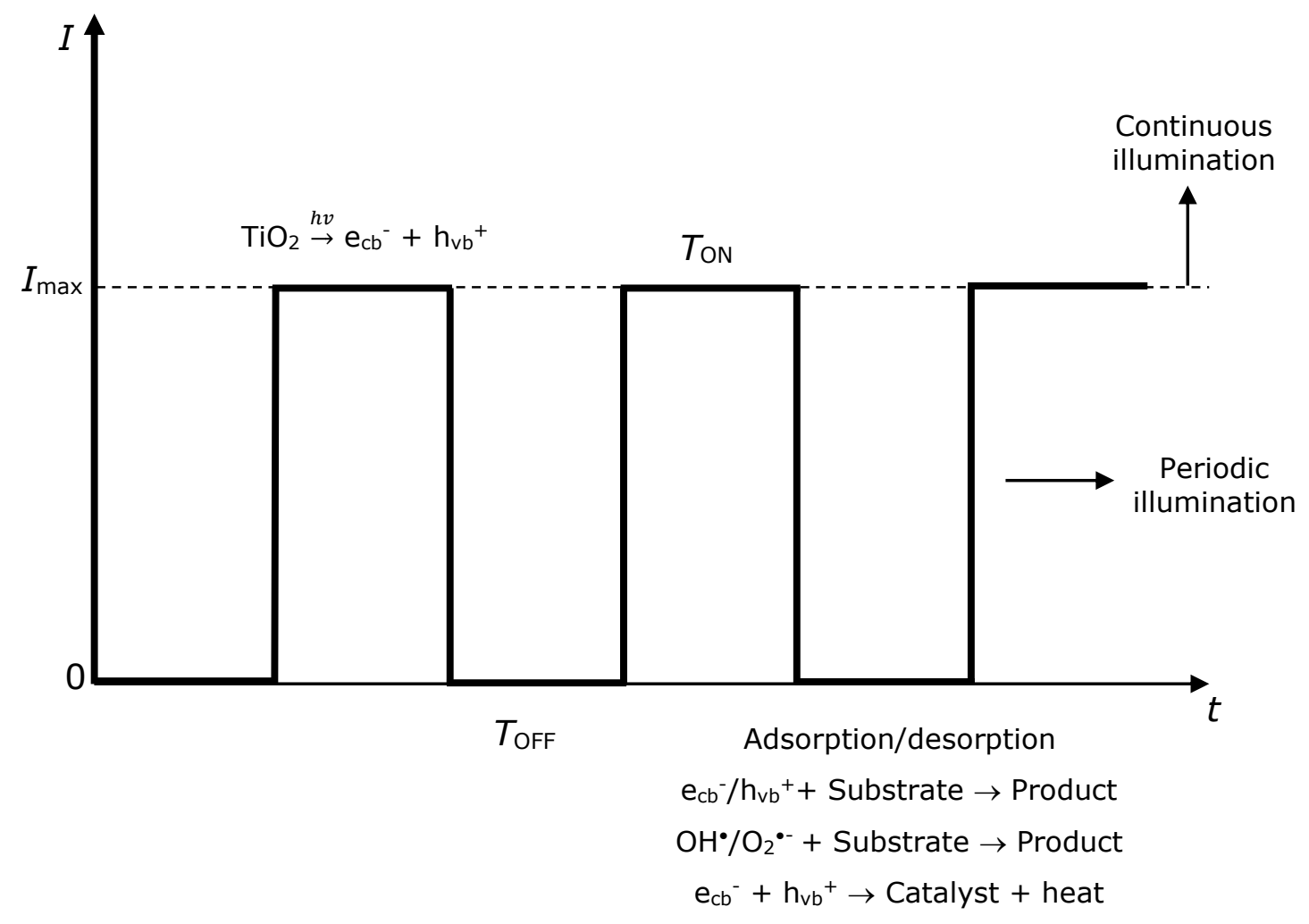

Figure 2.

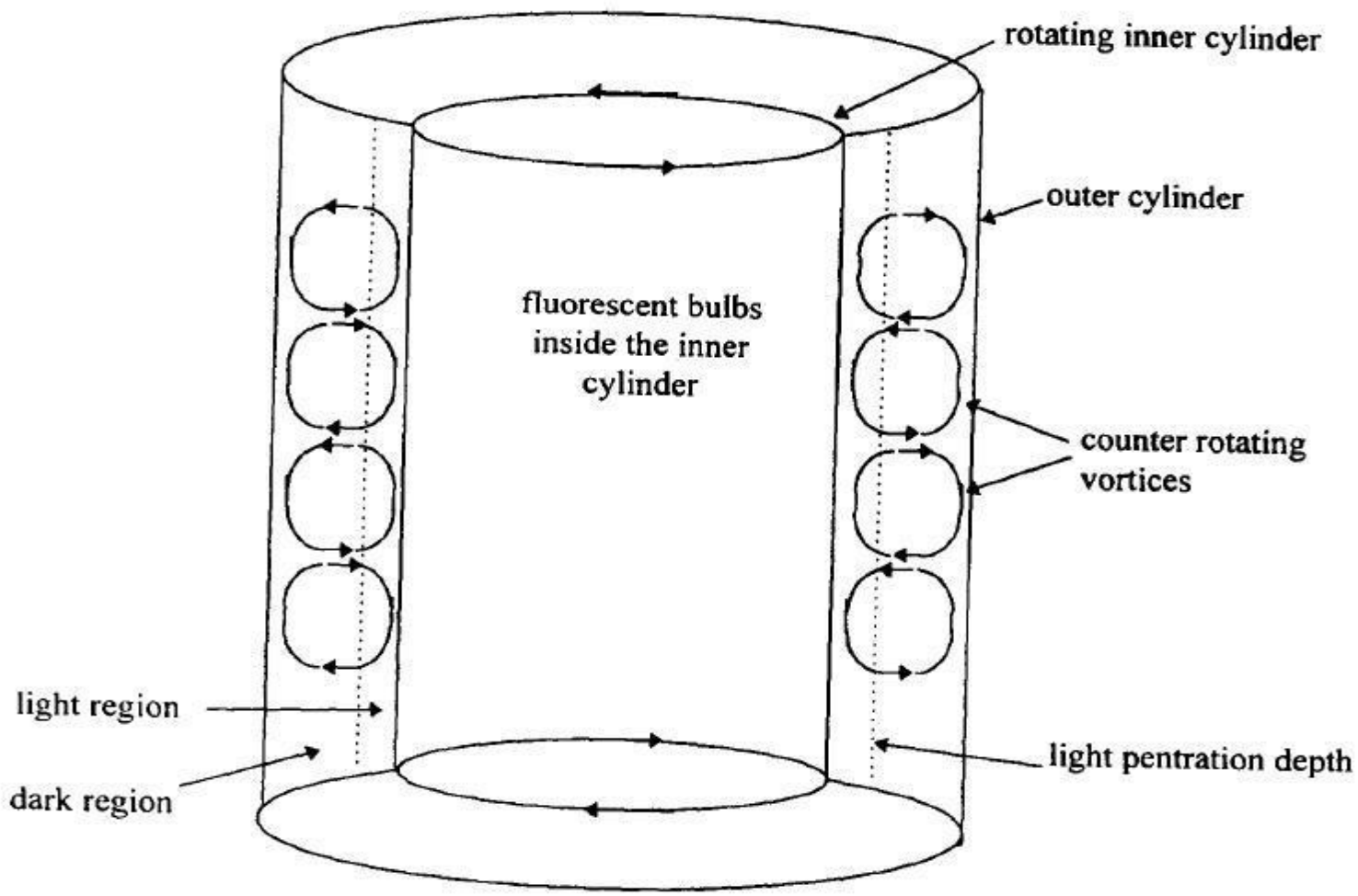

Figure 3. 


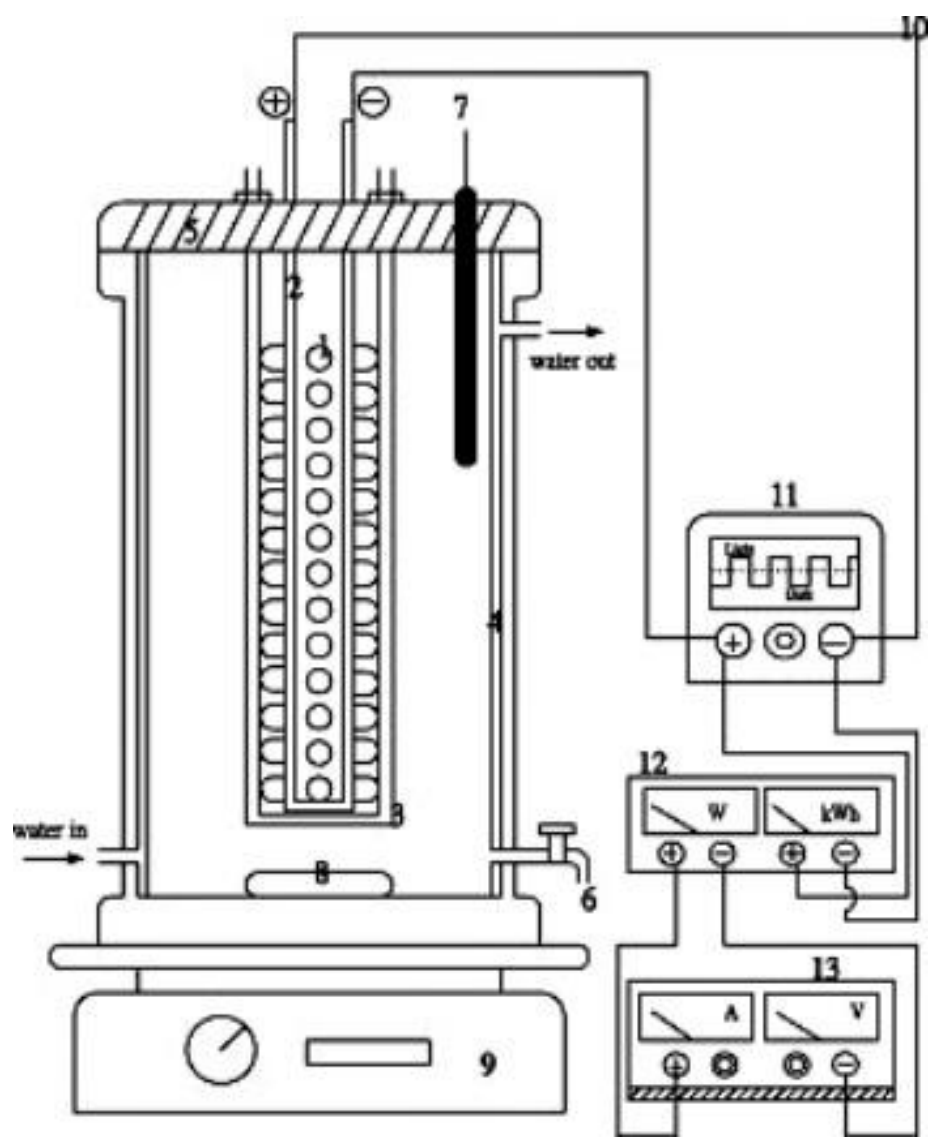

Figure 4.

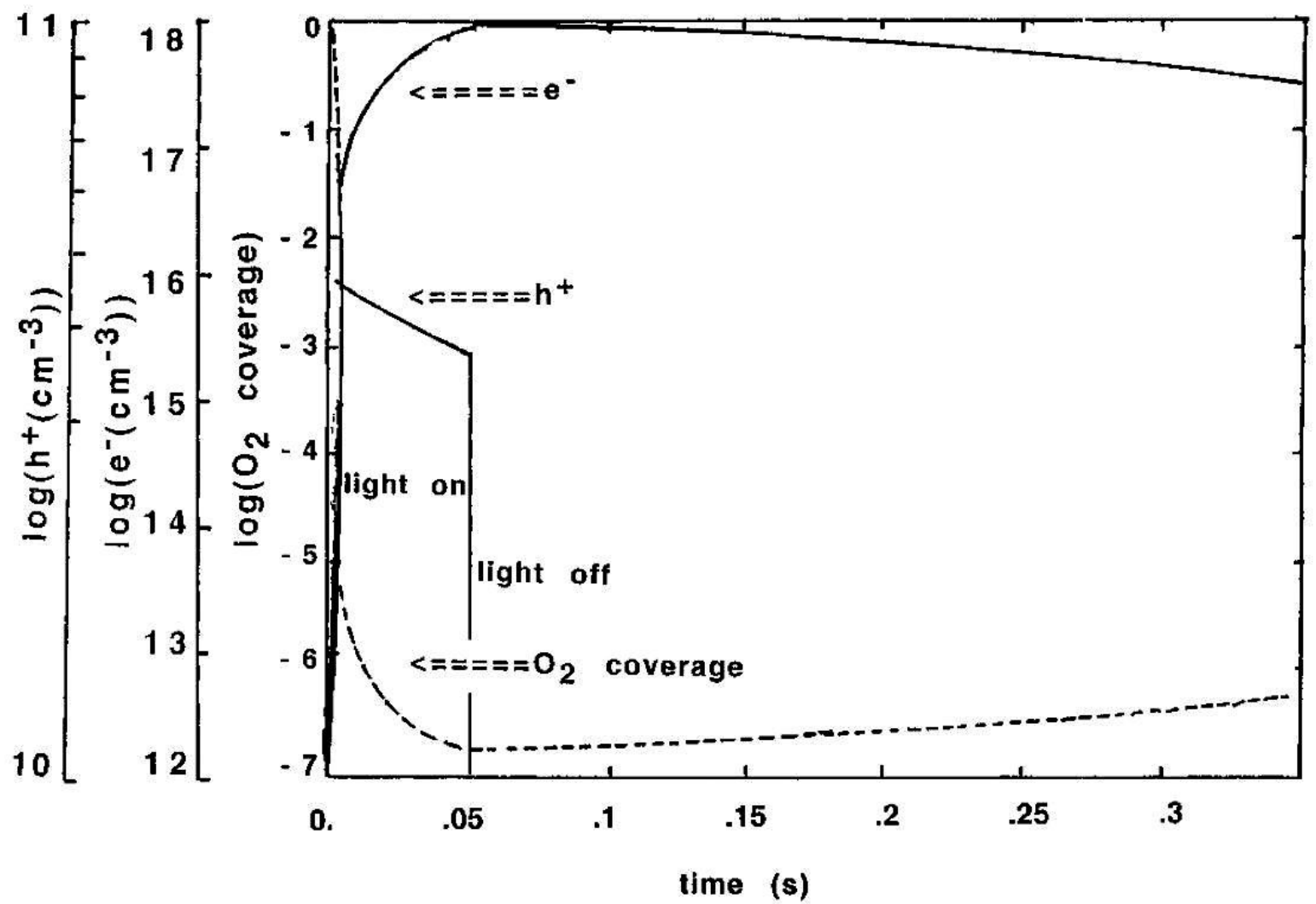

Figure 5. 


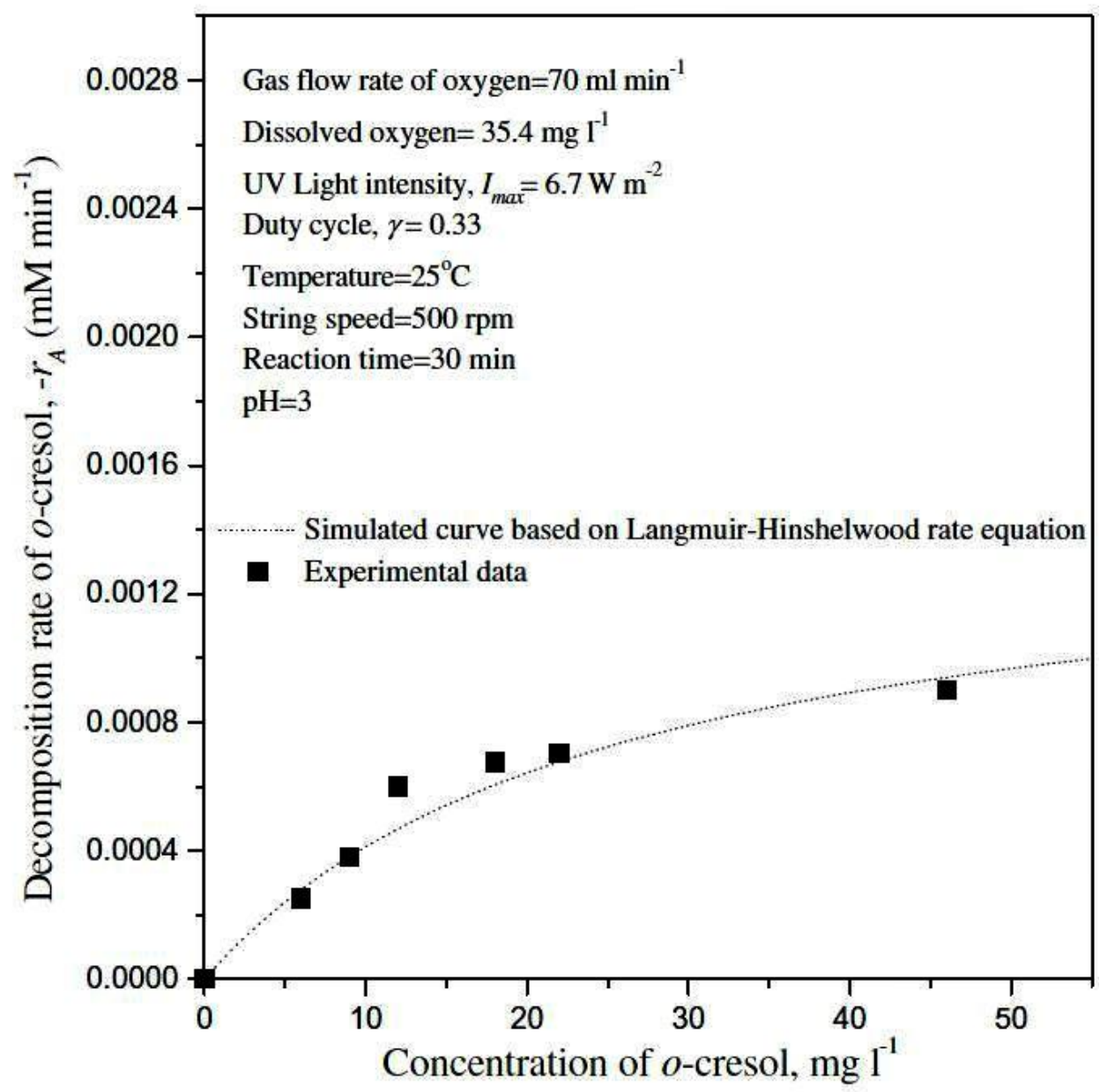

Figure 6. 


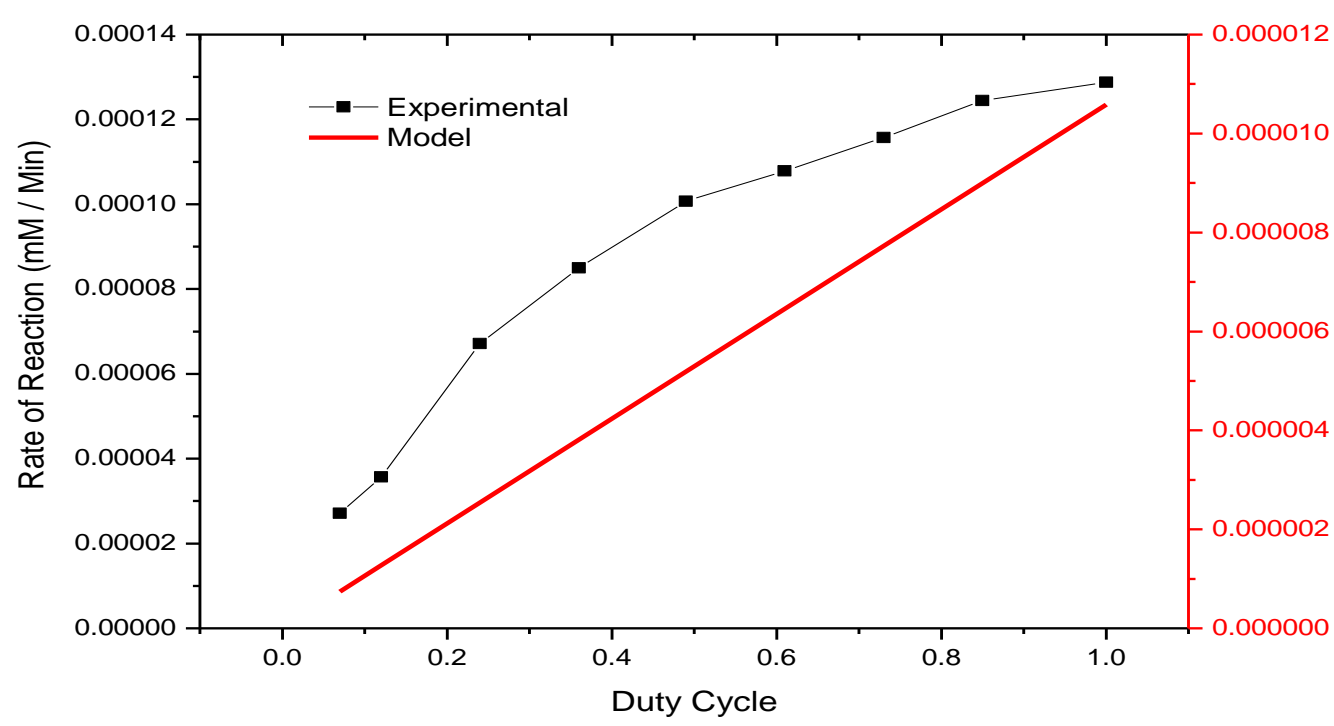

(a)

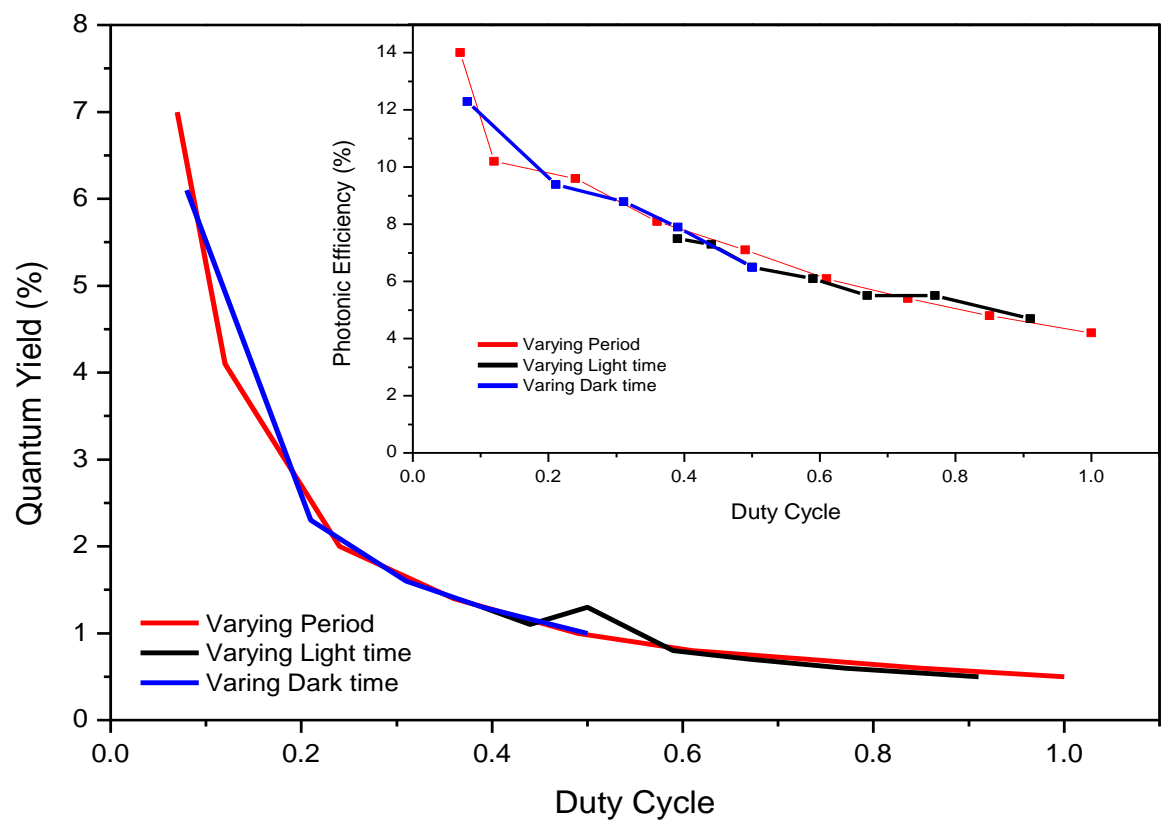

(b)

Figure 7. 


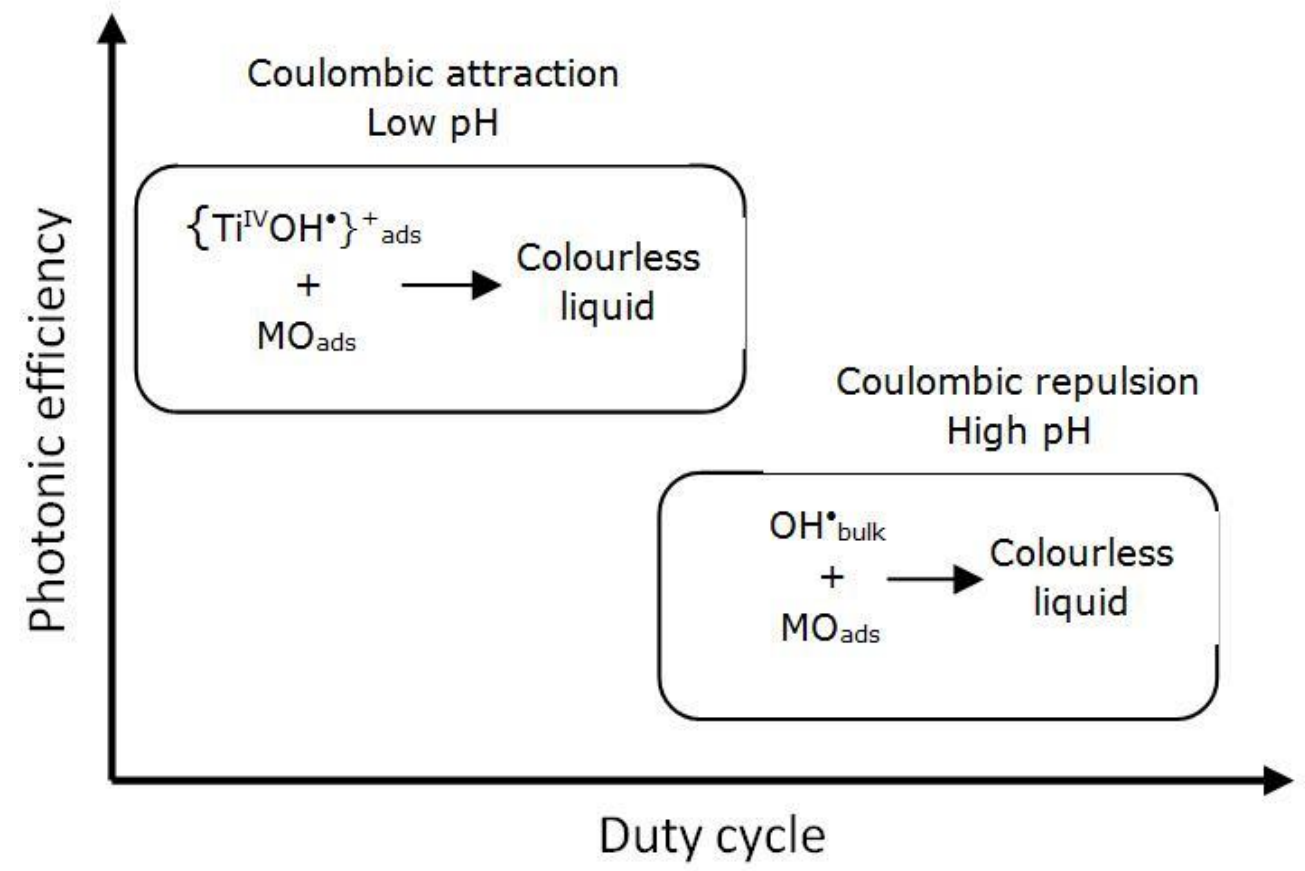

Figure 8. 


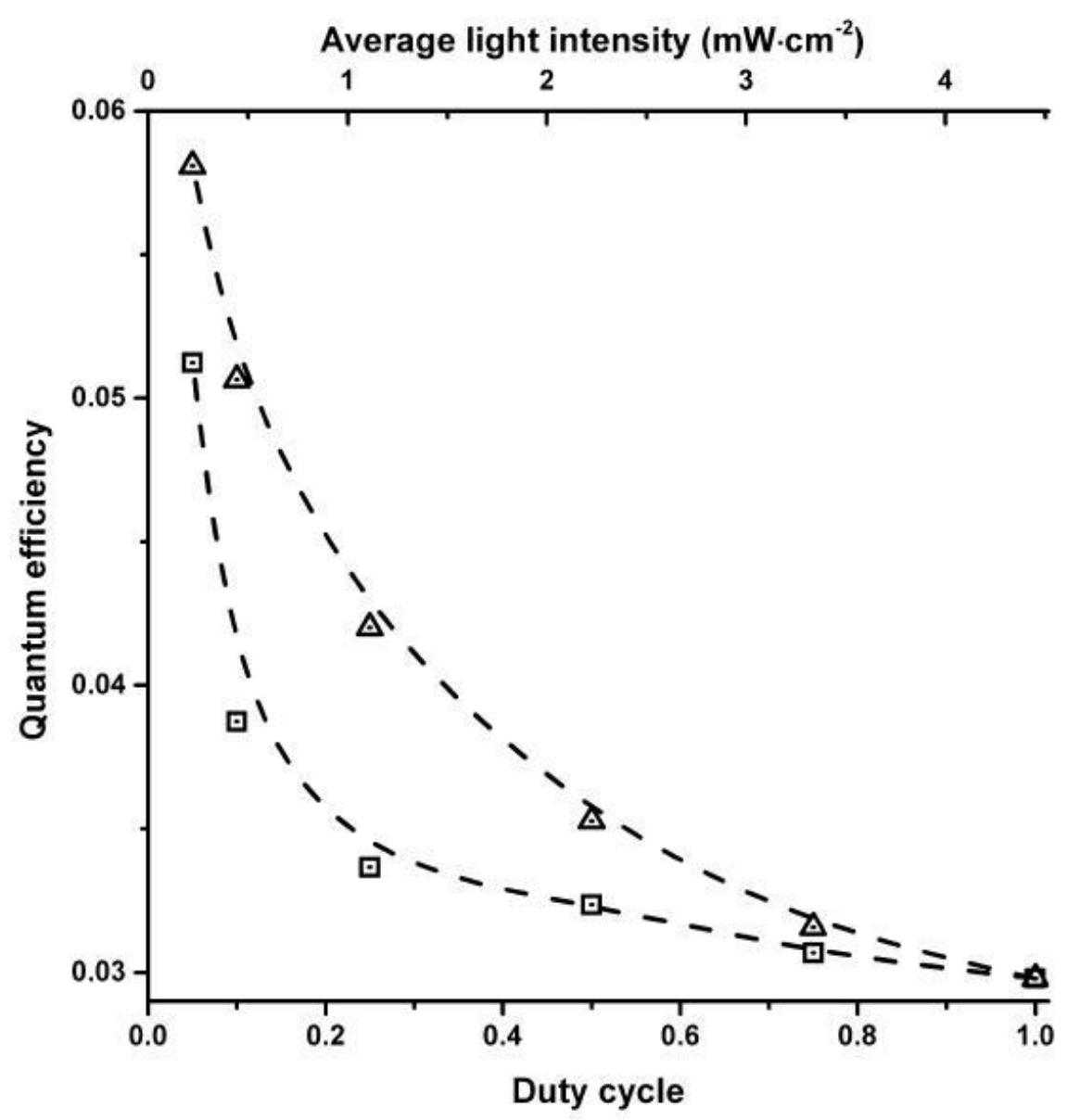

Figure 9. 